\title{
Antiplatelet, anticoagulant and fibrinolytic effects of Litchi chinensis Sonn. extract
}

\author{
YOON-YOUNG SUNG, WON-KYUNG YANG and HO KYOUNG KIM \\ Center of Herbal Resources Research, Korea Institute of Oriental Medicine, \\ Yuseong-gu, Daejeon 305-811, Republic of Korea
}

Received September 27, 2011; Accepted December 15, 2011

DOI: $10.3892 / \mathrm{mmr} .2011 .735$

\begin{abstract}
Litchi chinensis Sonn. (lychee), which belongs to the family of Sapindaceae, is a subtropical evergreen tree that is cultivated throughout Southeast Asia, particularly in China. Litchi chinensis has been reported to have anti-inflammatory, antioxidant and antidiabetic activities. However, the antiplatelet and anticoagulant effects of Litchi chinensis have not been reported previously. In this study, we investigated the effects of a $70 \%$ ethanol extract from Litchi chinensis (LCE) on platelet aggregation, coagulation and fibrinolysis. LCE dose-dependently inhibited collagen- and ADP-induced platelet aggregation in rat platelet-rich plasma. LCE at $4 \mathrm{mg} / \mathrm{ml}$ had a maximal inhibitory effect on platelet aggregation. In particular, the LCE $4 \mathrm{mg} / \mathrm{ml}$-treated group showed almost complete inhibition in the collagen-induced platelet aggregation assay. It also significantly prolonged coagulation times, such as the activated partial thromboplastin and prothrombin time, in rat platelet-poor plasma. We also investigated the fibrinolytic effects of LCE using the fibrin plate assay. LCE increased fibrinolytic activity in a dose-dependent manner. These results demonstrated the antithrombotic effects of LCE and suggest that Litchi chinensis may be a new natural source for the development of antiplatelet, anticoagulant and thrombolytic therapeutics for thrombotic and cardiovascular diseases.
\end{abstract}

\section{Introduction}

Platelets circulate in the blood and play essential roles in hemostasis and repair of the endothelial wall in a physiological state (1). This is achieved primarily by thrombus formation when

Correspondence to: Dr Ho Kyoung Kim, Center of Herbal Resources Research, Korea Institute of Oriental Medicine, 483 Exporo, Yuseong-gu, Daejeon 305-811, Republic of Korea E-mail: hkkim@kiom.re.kr

Abbreviations: APTT, activated partial prothrombin time; LCE, Litchi chinensis extract; PPP, platelet-poor plasma; PRP, platelet-rich plasma; PT, prothrombin time

Key words: cardiovascular, coagulation, Litchi chinensis, platelet aggregation, thrombotic damage occurs to the endothelial cell layer of blood vessels. However, excessive platelet aggregation produces a pathological thrombus and plays a major role in the initiation and pathogenesis of atherothrombotic diseases (2). An abnormal thrombus within the vascular system can obstruct the flow of blood and nutrients to important tissues. As a result, it can cause a variety of cardiovascular diseases, such as myocardial infarction, stroke and ischemic heart disease, and is a leading cause of death (3). Thus, inhibition of platelet aggregation is important in preventing the progression of atherosclerosis and arterial thromboses (4).

A thrombus is composed of fibrin, which is produced from its precursor, fibrinogen, by thrombin. An inappropriate fibrin clot must be eliminated rapidly by fibrinolysis to maintain homeostasis (5). Dissolution of a fibrin clot is dependent on the action of plasmin, a serine protease that is activated by tissue plasminogen activator. In clinical therapy, thrombolytic agents (fibrinolytic enzymes), such as tissue plasminogen activator and urokinase, convert inactive plasminogen to active plasmin, allowing fibrinolysis to occur (6). Antiplatelet agents, such as aspirin and clopidogrel, are widely used and directly inhibit platelet aggregation. However, use of these agents is limited as they can lead to serious side effects, such as headache, vomiting, and gastric ulceration, and are costly $(7,8)$.

Litchi chinensis Sonn. (lychee), which belongs to the family of Sapindaceae, is a subtropical evergreen tree that is cultivated throughout Southeast Asia, especially in China (9). Lychee fruit has a sweet odor and a delicious taste, and has been used in traditional medicine as a tonic for the liver, heart and brain (10). It has one of the highest polyphenol contents of any fruit (11).

Litchi chinensis has been reported to have anti-inflammatory (12), antioxidant (13), and antidiabetic (14) activities. However, the antiplatelet and anticoagulant effects of Litchi chinensis have not been reported previously. In this study, therefore, the inhibitory activities of Litchi chinensis extract (LCE) on platelet aggregation and coagulation were examined. The fibrinolytic effects of LCE were also investigated using a fibrin plate assay.

\section{Materials and methods}

Reagents. Fibrinogen, thrombin, and plasmin from human plasma were obtained from Sigma (St. Louis, MO, 
USA). Collagen and adenosine diphosphate (ADP) were purchased from Chrono-Log Corp. (Havertown, PA, USA). Thromboplastin and calcium chloride $(0.02 \mathrm{M})$ were purchased from Instrumentation Laboratory Co. (Milan, Italy).

Plant material and sample preparation. Litchi chinensis was purchased as a dried herb from Hanherb Co. (Seoul, Korea) and was authenticated based on its microscopic and macroscopic characteristics by the Classification and Identification Committee of the Korea Institute of Oriental Medicine. The committee is composed of 9 experts in the fields of plant taxonomy, botany, pharmacognosy and herbology. A voucher specimen (no. PH-14) was deposited at the herbarium of the Department of Herbal Resources Research.

Dried fruits of Litchi chinensis $(100 \mathrm{~g})$ were extracted twice with $70 \%$ ethanol ( $\mathrm{h}$ reflux), and the extract was concentrated under reduced pressure. The decoction was filtered, lyophilized and stored at $4^{\circ} \mathrm{C}$. The yield of the dried extract from starting crude materials was $8.31 \%(\mathrm{w} / \mathrm{w})$.

Animals. Male Sprague-Dawley rats were purchased from Dae-Han Biolink Co. (Eum sung, Korea) and acclimated for 1 week prior to the experiments. The animals were housed in an air-conditioned animal room with a 12/12-h light/dark cycle at a temperature of $22 \pm 1^{\circ} \mathrm{C}$ and humidity of $50 \pm 10 \%$. The animals were provided with a laboratory diet and water ad libitum. All experimental protocols involving the use of animals were conducted in accordance with National Institutes of Health (NIH) guidelines and approved by the Committee on Animal Care.

Preparation of platelets. Platelet-rich plasma (PRP) was obtained by centrifuging rat blood samples at $180 \mathrm{x}$ g for $10 \mathrm{~min}$, and platelet-poor plasma (PPP) was obtained by centrifuging the PRP at 2,100 $\mathrm{x}$ g for $10 \mathrm{~min}$. PRP was adjusted to $3 \times 10^{8}$ platelets $/ \mathrm{ml}$ with PPP. The number of platelets was counted using a Coulter Counter (Coulter Electronics, Inc., Hialeah, FL, USA).

Platelet aggregation assay. Antiplatelet aggregation activity was investigated as described previously (15), using an aggregometer (Chrono-Log Corp.). Rat PRP (245 $\mu 1)$, prepared as above, was incubated at $37^{\circ} \mathrm{C}$ in cuvettes in the aggregometer with stirring at $1,000 \mathrm{rpm}$, and $2.5 \mu \mathrm{l} 3 \%$ dimethyl sulfoxide (control group) or various concentrations of LCE were added. After a 3-min preincubation, platelet aggregation was induced by addition of collagen $(10 \mu \mathrm{g} / \mathrm{ml})$ or ADP $(10 \mu \mathrm{M})$. Changes in light transmission were recorded for 6 min after induction.

Coagulation assays. PPP was obtained as described above. Briefly, $120 \mu \mathrm{l}$ plasma was mixed with $40 \mu \mathrm{l}$ various concentrations of LCE, and the plasma mixture was incubated at $37^{\circ} \mathrm{C}$ for $5 \mathrm{~min}$. Coagulation was started by adding thromboplastin and calcium chloride for the prothrombin time (PT) and activated partial thromboplastin time (APTT) assays, respectively. PT and APTT values were measured using an Automated Coagulation Laboratory 7000 Instrument (Instrumentation Laboratory, Milan, Italy). Heparin was used as a reference $\operatorname{drug}(11.2 \mu \mathrm{g} / \mathrm{ml}$ for PT and $1.4 \mu \mathrm{g} / \mathrm{ml}$ for APTT).
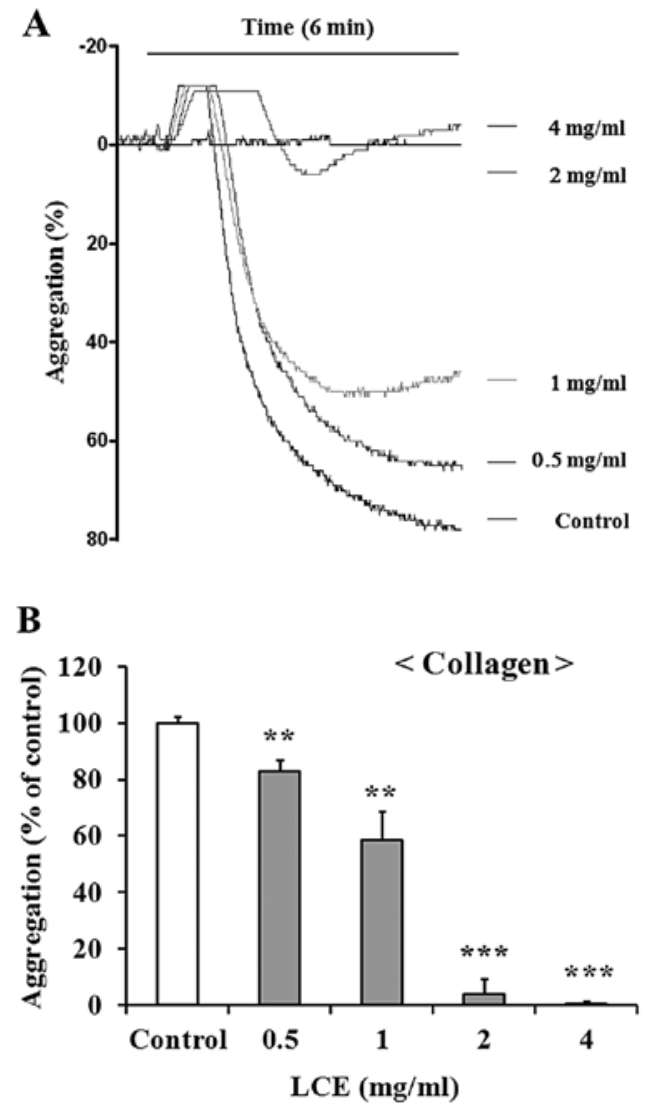

Figure 1. Effect of Litchi chinensis extract on platelet aggregation induced by collagen in rat platelet-rich plasma (PRP). (A) The aggregation pattern shows the change in platelet aggregation (\%) by time and (B) the graph shows quantitative data, based on the maximal platelet aggregation pattern in each group. Platelet aggregation was induced by collagen $(10 \mu \mathrm{g} / \mathrm{ml})$. Data are expressed as mean $\pm \mathrm{SD}$ of three independent experiments. ${ }^{* *} \mathrm{P}<0.01$ and ${ }^{* * *} \mathrm{P}<0.001$, compared with the control group.

Fibrin plate assay for fibrinolytic activity. Fibrinolytic activity was determined using a fibrin plate assay (16). A fibrin plate was made in a Petri dish at room temperature with $0.6 \%$ human fibrinogen and $50 \mathrm{NIH}$ units of human thrombin. The dishes were left for $30 \mathrm{~min}$ at room temperature to allow the fibrin layer to form. Samples $(50 \mu \mathrm{l})$ were loaded on the fibrin plate at $37^{\circ} \mathrm{C}$ for $15 \mathrm{~h}$. Plasmin from human plasma was used as a reference drug. Fibrin plate clearance was monitored by measuring 2 perpendicular diameters of the cleared zone. Fibrinolytic activities were expressed as the clear zone area.

Statistical analyses. All data are presented as means \pm SD. The differences between groups were examined using an unpaired Student's t-test. Differences were considered significant at a $\mathrm{P}$-value $<0.05$.

\section{Results}

Effect of LCE on platelet aggregation. The effect of LCE on agonist-induced platelet aggregation was evaluated using rat PRP. As shown in Figs. 1 and 2, LCE inhibited collagen- and ADP-induced platelet aggregation in a dose-dependent manner. LCE at $4 \mathrm{mg} / \mathrm{ml}$ had maximal inhibitory effect on collagen $(10 \mu \mathrm{g} /$ $\mathrm{ml})$ - and $\mathrm{ADP}(10 \mu \mathrm{M})$-induced platelet aggregation $(0.42 \pm 0.74$ 
A

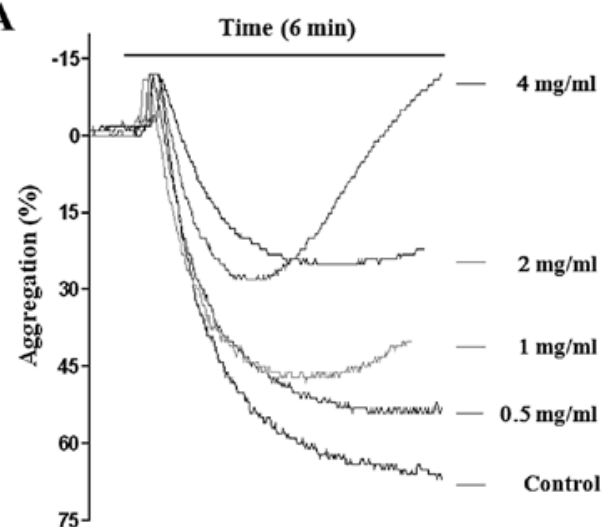

B

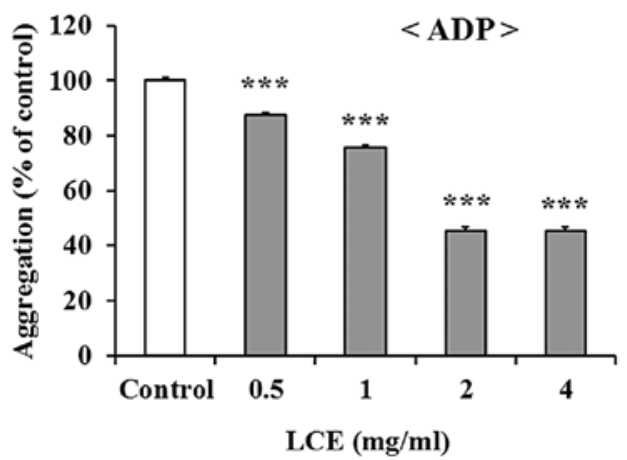

Figure 2. Effect of Litchi chinensis extract on platelet aggregation induced by adenosine diphosphate (ADP) in rat platelet-rich plasma (PRP). (A) The aggregation pattern shows the change in platelet aggregation (\%) by time and (B) the graph shows quantitative data, based on maximal platelet aggregation pattern in each group. Platelet aggregation was induced by ADP $(10 \mu \mathrm{M})$. Data are expressed as means \pm SD of three independent experiments. ${ }^{* * * *} \mathrm{P}<0.001$, compared with the control group.

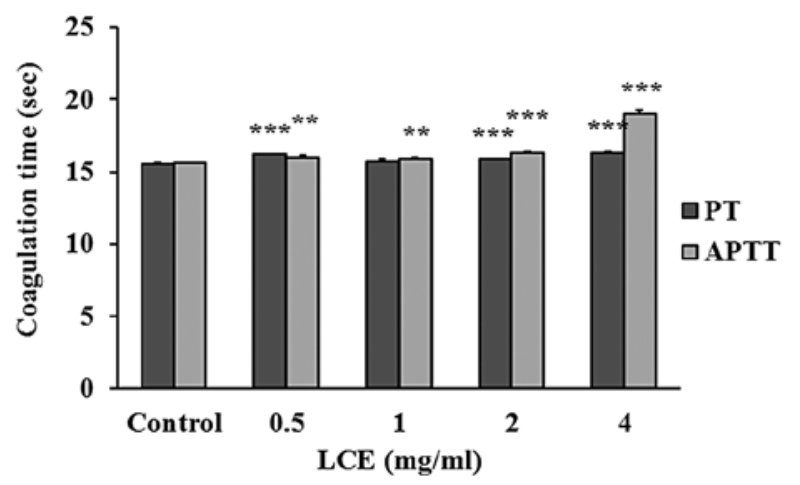

Figure 3. Effect of Litchi chinensis extract on coagulation times in rat PPP. PPP was obtained by centrifuging PRP at 2,100 x g for $10 \mathrm{~min}$, and the APTT and PT were measured as described in Materials and methods. Data are expressed as means $\pm \mathrm{SD}$ of three independent experiments. ${ }^{* *} \mathrm{P}<0.01$ and ${ }^{* * *} \mathrm{P}<0.001$, compared with the control group. PPP, platelet-poor plasma PRP, platelet-rich plasma; APTT, activated partial thromboplastin time; PT, prothrombin time.

and $45.62 \pm 6.17 \%$ ). In particular, the LCE $4 \mathrm{mg} / \mathrm{ml}$-treated group showed almost complete inhibition in the collagen-induced platelet aggregation assay. Half inhibitory concentration $\left(\mathrm{IC}_{50}\right)$ values of LCE for collagen- and ADP-induced platelet aggregation were 1.01 and $2.04 \mathrm{mg} / \mathrm{ml}$, respectively.
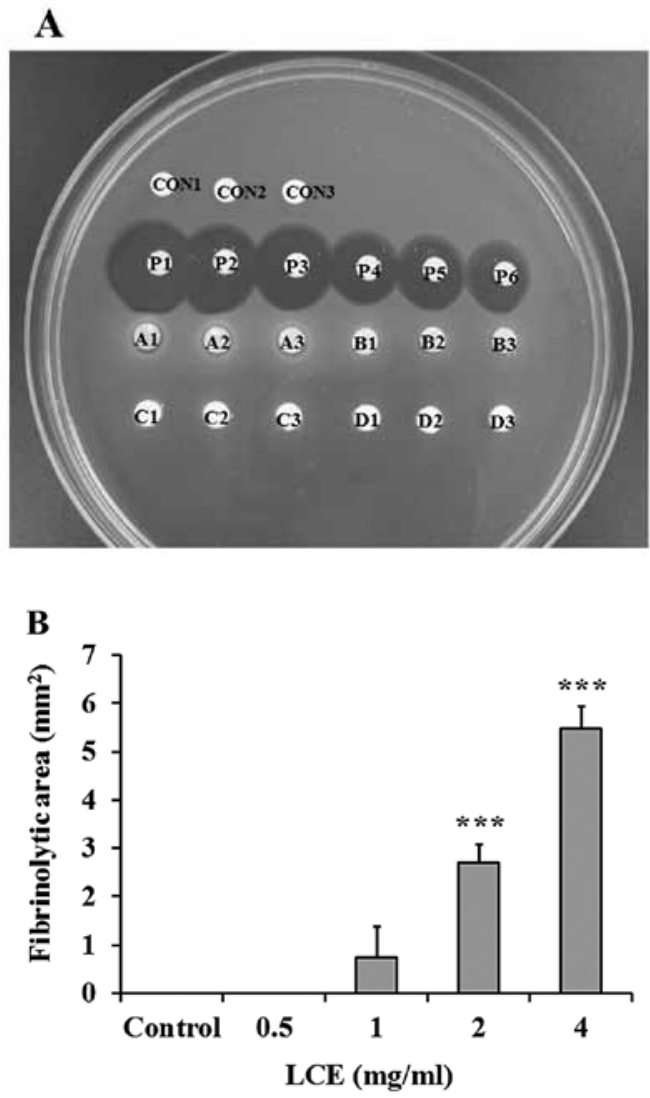

Figure 4. Effect of Litchi chinensis extract on fibrinolysis. (A) Representative images of a Litchi chinensis fibrin plate. CON, control; P1-3, plasmin $2 \mu \mathrm{g}$; P4-6, plasmin $1 \mu \mathrm{g}$; A1-3, LCE $4 \mathrm{mg} / \mathrm{ml}$; B1-3, LCE $2 \mathrm{mg} / \mathrm{ml}$; C1-3, LCE $1 \mathrm{mg} / \mathrm{ml}$; D1-3, LCE $0.5 \mathrm{mg} / \mathrm{ml}$. (B) Measurement of the fibrinolytic area in a Litchi chinensis fibrin plate. Data are expressed as means \pm SD of three independent experiments. ${ }^{* * *} \mathrm{P}<0.001$, compared with the control group.

Effect of LCE on coagulation time. The effects of LCE on coagulation times, including PT and APTT, were evaluated at different concentrations. PT and APTT in the control group were $15.57 \pm 0.06$ and $15.60 \pm 0.00 \mathrm{sec}$, respectively. Heparin, which served as a reference drug, showed statistically significant prolongation of PT and APTT (20.20 \pm 0.52 and $38.90 \pm 3.70 \mathrm{sec}$, respectively). LCE significantly prolonged PT and APTT at all concentrations tested, when compared with the control group (Fig. 3). In particular, APTT was prolonged by treatment with LCE in a dose-dependent manner. LCE at $4 \mathrm{mg}$ / $\mathrm{ml}$ had maximal prolonged effect on APTT $(19.03 \pm 0.21 \mathrm{sec})$.

Effect of LCE on fibrinolysis. In the fibrin plate assay, fibrinolysis was increased by LCE treatment in a dose-dependent manner (Fig. 4). LCE significantly induced fibrinolysis at 2 and $4 \mathrm{mg} / \mathrm{ml}$, when compared with the control group $(2.69 \pm 0.39$ and $5.46 \pm 0.47$ vs. $0.00 \pm 0.00 \mathrm{~mm}^{2}$, respectively). Plasmin (1 and $2 \mu \mathrm{g}$ ), which served as a reference, showed significant fibrinolytic activity (Fig. 4A).

\section{Discussion}

The results of this study demonstrated that LCE inhibited platelet aggregation and increased coagulation times, such as the PT and activated APTT and fibrinolysis. These results 
indicate that Litchi chinensis may have the potential to prevent thrombotic and cardiovascular diseases, which may be due to antiplatelet, anticoagulation and fibrinolytic effects.

Inappropriate thrombus formation is related to a failure in homeostasis, and the major elements involved are coagulation factors, platelets and blood vessels (17). To investigate the activity of LCE in the coagulation process, we measured PT and APTT to evaluate the extrinsic and intrinsic routes of coagulation, respectively. PT is specifically altered when there are deficiencies in extrinsic coagulation factors, such as II, VII and $X$. On the other hand, deficiencies in intrinsic coagulation factors, such as VIIIc, IX, XI and XII, are responsible for increased APTT (18). In this study, LCE increased PT and APTT, when compared with the control group (Fig. 3). The increased coagulation times in the intrinsic and extrinsic routes of coagulation are related to a delay in the coagulation process, due to slower fibrin blood clot formation (19).

Platelets play essential roles in hemostasis, but platelet aggregation is a major cause of atherothrombotic diseases. When there is injury to a blood vessel wall or endothelial cell layer, platelets adhere to the damage site by binding to von Willebrand factor and collagen in the sub-endothelial matrix. Next, platelets are stimulated to release various molecules, such as thrombin, thromboxane $\mathrm{A}_{2}$, and ADP, to activate other platelets, and to increase the expression of glycoprotein IIb/IIIa receptors for fibrinogen binding. These processes lead to the formation of a platelet plug at the damaged endothelial site $(20,21)$.

The results of the present study showed that LCE inhibited collagen- and ADP-induced platelet aggregation in a concentration-dependent manner (Fig. 1 and 2), indicating that Litchi chinensis has potential antithrombotic activity. However, in this study, in vivo antithrombotic effects and the antiplatelet mechanisms of action of LCE were not examined. Further studies on these effects of LCE are now in progress.

Additionally, the present results showed that LCE has fibrinolytic activity, and suggest that Litchi chinensis may also be useful in thrombolytic therapy. Thrombolytic agents are classified according to their fibrinolysis mechanisms. Plasmin activator converts plasminogen to active plasmin for fibrinolysis. Plasmin-like proteins, which have been discovered in fermented foods, perform fibrinolysis directly (22). Further study is necessary to purify and characterize Litchi chinensisderived fibrinolytic components.

In conclusion, the present results indicate that LCE has a potent antithrombotic effect, inhibiting platelet aggregation, delaying coagulation time, and increasing fibrinolysis. Litchi chinensis may be a new natural source for the development of antiplatelet, anticoagulant and thrombolytic therapeutics for thrombotic and cardiovascular diseases.

\section{Acknowledgements}

This study was supported by the project 'Discovery of Herbal Medicine for the Prevention of Prehypertension' (K11202) from the Ministry of Education, Science and Technology of Korea.

\section{References}

1. Packham MA: Role of platelets in thrombosis and hemostasis. Can J Physiol Pharmacol 72: 278-284, 1994.

2. Davi G and Patrono C: Platelet activation and atherothrombosis. N Engl J Med 357: 2482-2494, 2007.

3. Haines ST and Bussey HI: Thrombosis and the pharmacology of antithrombotic agents. Ann Pharmacother 29: 892-905, 1995.

4. Ruggeri ZM: Platelets in atherothrombosis. Nat Med 8: $1227-1234,2002$

5. Medved L and Nieuwenhuizen W: Molecular mechanisms of initiation of fibrinolysis by fibrin. Thromb Haemost 89: 409-419, 2003.

6. Collen D and Lijnen HR: Thrombolytic agents. Thromb Haemost 93: 627-630, 2005.

7. Ueshima $\mathrm{S}$ and Matsuo O: Development of new fibrinolytic agents. Curr Pharm Des 12: 849-857, 2006.

8. Angiolillo DJ, Fernandez-Ortiz A, Bernardo E, Alfonso F, Macaya C, Bass TA and Costa MA: Variability in individual responsiveness to clopidogrel: clinical implications, management, and future perspectives. J Am Coll Cardiol 49: 1505-1516, 2007.

9. Zhao M, Yang B, Wang J, Liu Y, Yu L and Jiang Y: Immunomodulatory and anticancer activities of flavonoids extracted from litchi (Litchi chinensis Sonn) pericarp. Int Immunopharmacol 7: 162-166, 2007.

10. Bhoopat L, Srichairatanakool S, Kanjanapothi D, Taesotikul T, Thananchai H and Bhoopat T: Hepatoprotective effects of lychee (Litchi chinensis Sonn.): a combination of antioxidant and antiapoptotic activities. J Ethnopharmacol 136: 55-66, 2011.

11. Brat P, Georgé S, Bellamy A, Du Chaffaut L, Scalbert A, Mennen L, Arnault N and Amiot MJ: Daily polyphenol intake in France from fruit and vegetables. J Nutr 13: 2368-2373, 2006.

12. Besra SE, Sharma RM and Gomes A: Antiinflammatory effect of petroleum ether extract of leaves of Litchi chinensis Gaertn. (Sapindaceae). J Ethnopharmacol 54: 1-6, 1996.

13. Yang B, Wang J, Zhao M, Liu Y, Wang W and Jiang Y: Identification of polysaccharides from pericarp tissues of litchi (Litchi chinensis Sonn.) fruit in relation to their antioxidant activities. Carbohydr Res 341: 634-638, 2006.

14. Guo J,Li L,Pan J,Qiu G,Li A,Huang G and Xu L: Pharmacological mechanism of Semen Litchi on antagonizing insulin resistance in rats with type 2 diabetes. Zhong Yao Cai 27: 435-438, 2004 (In Chinese).

15. Jin YR, Ryu CK, Moon CK, Cho MR and Yun YP: Inhibitory effects of J78, a newly synthesized 1,4-naphthoquinone derivative, on experimental thrombosis and platelet aggregation. Pharmacology 70: 195-200, 2004.

16. Jung KA, Song TC, Han D, Kim IH, Kim YE and Lee CH: Cardiovascular protective properties of kiwifruit extracts in vitro. Biol Pharm Bull 28: 1782-1785, 2005.

17. Azevedo AP, Farias JC, Costa GC, Ferreira SC, Aragão-Filho WC, Sousa PR, Pinheiro MT, Maciel MC, Silva LA, Lopes AS, Barroqueiro ES, Borges MO, Guerra RN and Nascimento FR: Anti-thrombotic effect of chronic oral treatment with Orbignya phalerata Mart. J Ethnopharmacol 111: 155-159, 2007.

18. Gailani D and Broze GJ Jr: Factor XI activation in a revised model of blood coagulation. Science 253: 909-912, 1991.

19. Riewald $M$ and Ruf W: Science review: role of coagulation protease cascades in sepsis. Crit Care 7: 123-129, 2003.

20. Steinhubl SR and Moliterno DJ: The role of the platelet in the pathogenesis of atherothrombosis. Am J Cardiovasc Drugs 5: 399-408, 2005.

21. Vorchheimer DA and Becker R: Platelets in atherothrombosis. Mayo Clin Proc 81: 59-68, 2006.

22. Mine Y, Wong AHK and Jiang B: Fibrinolytic enzymes in Asian traditional fermented foods. Food Res Int 38: 243-250, 2005. 